\title{
Posthumous Harm in the History of Medicine
}

\begin{abstract}
Posthumous harm, in the first instance, is understood in the context of Alder Hey Hospital in Liverpool, where in the late twentieth century improper procurement and retention of organs and other human materials, supposedly under the auspices of medical research, occurred against the express wishes of the next of kin.

The notion of posthumous harm is first explored more formally, through a public inquiry, which found that institutional failures aggravated the original harm of the improper removal and retention of organs. It is then explored more deeply, through the parental oral evidence to The Royal Liverpool Children's Inquiry Report (2001b). From the perspective of grieving family and friends, posthumous harm is constitutive of: a breach of proper consent; an assault on grief and memory; as well as a contravention of religious belief and funerary custom.

The counterpoint to posthumous harm is the notion of posthumous redemption. From the point of view of the medical professional, the cadaver is a redemptive force in medicine; it is a resource for saving lives (cadaveric organ donation), medical research and medical education and training. While the intention behind the improper post-mortems at Alder Hey was medically redemptive, organs and tissues were stored away and largely unused.

Posthumous harm and redemption are finally understood from the historical long-view. This chapter ends with a comparative view between body-snatching in the Georgian period and 'organ-snatching' at Alder Hey two hundred odd years later.
\end{abstract}

(C) The Author(s) 2017

F. Tomasini, Remembering and Disremembering the Dead, Palgrave Historical Studies in the Criminal Corpse and its Afterlife, DOI 10.1057/978-1-137-53828-4_5 
Keywords Alder Hey · Body-snatching · Organ-snatching · Posthumous Harm · Redfern · Symbolic Harm and Violence

\section{Contemporary Perspectives on Posthumous Harm and Redemption: Alder Hey}

\section{An Overview of Events}

One of the most infamous examples of posthumous harm in contemporary times arises out of the organ retention scandal at Alder Hey Hospital in Liverpool in the 1990s.

Awareness of the retention of organs at Alder Hey arose from an altogether separate public inquiry into the unusually high infant mortality rate after cardiac surgery at the Bristol Royal Infirmary. On 7 September 1999, the heart specialist Professor Anderson of Great Ormond Street gave evidence to the Bristol Inquiry. In his evidence, Anderson pointed out the advantages of post-mortem retention of hearts for research and teaching purposes. In particular he mentioned the impressive collection of hearts held at Alder Hey Children's Hospital, which dated from 1948 (Hall 2001; Harrison et al. 2003, p. 49).

Anderson's observation was picked up by the local media on 18 September 1999, when two days later Ms. Hilary Roland, the Chief Executive of Alder Hey, gave assurances that the retention of organs was not dissimilar to that of other hospitals. The news caused enquiries from potentially affected parents of deceased children wanting to ascertain whether their children's organs had been retained. (Harrison et al. 2003 p. 49) After further investigations by the hospital management it was found that Ms. Rowland's initial assurances had been premature when it was discovered that the Professor of Pathology, Dick van Velzen, had authorised the retention of multiple organs, tissue fragments and whole foetuses, mainly in the basement at Myrtle Street.

Many parents were affected: 2080 organs had been removed and retained from 800 children and stored in pots. In addition, 1500 foetuses were also discovered in storage-either miscarried, stillborn, or aborted without consent (Batty 2001). For a single hospital, the retention figures were huge.

Parents wanted to know whether their children's organs had been retained, and wanted them located and returned for reinterment. The 
hospital failed to meet parental demands. The general feeling amongst parents was that the hospital was mismanaging information and or deceiving them as to what had happened to their children. In response, a support group was formed: Parents who Inter Their Young Twice (PITY2). This provided a self-supporting environment and a more organised and effective voice in dealing with hospital management.

On December 3, 1999 the new coroner for Liverpool suggested that the retention of organs had been unlawful, heightening parental concern and anxiety and launching Alder Hey back into the media spotlight once more. This and the prima facie evidence of wrong-doing and mismanagement culminated in the government announcing an independent Public Inquiry chaired by Michael Redfern QC in early 2000. Meanwhile the relationship between the hospital and the affected parents continued to worsen: parents complaining that the hospital was misleading them into believing they had buried their children intact when in fact they had not. Instead, most of the human material from the children of affected parents was stored unused (Harrison et al. 2003, p. 50).

The Alder Hey organ retention scandal was thoroughly investigated through a public inquiry. The results of which were reported on at length in The Royal Liverpool Children's Inquiry Report by Michael Redfern QC. This was published in January 2001. The Redfern Inquiry (2001), or simply 'Redfern' as it will be referred to from here on in, reported on the worst organ removal and retention scandal in Britain. When talking about Redfern, it is worth distinguishing between the summary and recommendations of the Inquiry Report (2001a) and the full Inquiry Report (2001b).

Redfern provides a helpful window into understanding:

- Problems with the practice of improper procurement, retention and storage of human material. This is discussed in a summary of Redfern's formal conclusions. It also provides recommendations of how it might be remedied;

- Why the posthumous harm of improper procurement, retention, storage and disposal affected parents so deeply. Much of the material about parents' emotional reaction in the parental oral evidence is available from the full Inquiry Report. This evidence provides insight into parents' inner lives and why posthumous harm matters to the next of kin in the first place. This is discussed in the parental oral evidence to Redfern. 


\section{A Short Summary of Redfern's Formal Conclusions}

The Redfern Inquiry summary and recommendations provide an incisive formal account of what went wrong at Alder Hey. While the summary begins with the misconduct of the head of pathology, the failures are institutionally endemic.

\section{The Misconduct of Persons: Professor Dick van Velzen}

Much of the furore around the retention scandal focused on the activities of Professor Dick van Velzen, the Head of the Foetal and Infant Pathology Unit at the University of Liverpool, and honorary paediatric pathologist at Alder Hey from 1988 to 1995.

It was clear from the very start that van Velzen's activities as a pathologist were divergent from the norm. Within a week of taking up his position, van Velzen issued the instruction that there was to be no disposal of human material. He wanted 'every organ removed in every case' (Redfern 200la, p. 8). Before van Velzen, pathologists had only retained sections of organs and the heart, lungs or brain in relevant cases. Naturally the store of human material started to grow to support his research interests, which he justified on the basis of developing a resource which he could exploit depending on the direction his research developed in the future.

Van Velzen's professional misconduct was extensive and is thoroughly documented in Redfern (2001a, 2001b).

What follows is an illustrative and non-exhaustive list of what Redfern found van Velzen guilty of:

- lying to patients generally and lying to them about his post-mortem findings more specifically;

- deceiving both Alder Hey and the university;

- unethical and illegal retention of organs;

- falsifying research applications, post-mortem reports and encouraging staff to falsify records and statistics;

- ignoring consent that stated a preference for limited post-mortems;

- failing to keep proper records of stored organs, and failing to maintain proper accounting procedures (Redfern 2001a, pp. 9-10).

Redfern's recommendations were designed to stop malpractice by rogue individuals like van Velzen. This was largely achieved by augmenting 
a trust in systems; where trust at the level of the institution is about accountability and 'super' accountability that can no longer afford to take the risk of employing untrustworthy persons (Pilgrim et al. 2011).

Redfern marked a shift from a paternalistic culture which stressed a blind trust in individuals to trust in institutions and institutional procedures and systems where hospitals had to be more accountable for: whom they employed; how they openly and honestly dealt with serious incidents as they arose; and how they implemented consent and reporting procedures (Harrison et al. 2003; Pilgrim et al. 2011).

\section{Relationship Between the University and the Hospital}

Michael Redfern remarked on the uncooperative relationship between the University and Alder Hey, culminating in the University distancing itself from the hospital once news of the retention scandal broke. He observed how this difficult relationship between the two institutions provided an opportunity for van Velzen to play one institution off against the other in support of his own agenda. Redfern concluded that van Velzen's worst excesses might have been prevented had the institutions had a better relationship. This prompted Redfern to recommend that institutions with dual clinical and academic functions had to develop relationships that 'fostered good faith in both directions' (Redfern 2001a, p. 15).

\section{The Role of the Coroner}

Michael Redfern discovered multiple failings. Clinicians were not always sure under what circumstances death had to be reported to the coroner. The coroner sometimes wrongly delegated post-mortems to the coroner's office. The coroner also did not follow up requests on histology with van Velzen, exacerbating the incompleteness of post-mortems and the illegal retention for research purposes. Some clinicians had been abusing the system by threatening parents with mandatory coroner's post-mortems in order to put pressure on them to agree to a voluntary hospital post-mortem (Redfern 2001a, p. 4). He concluded that failures in understanding the coroner's role contributed to a delay in identifying van Velzen's malpractice.

The role of the coroner needed to be clearly established. Redfern's recommendations spelled out the role of the coroner and a need for clinicians to be educated in proper procedures that involved the coroner's office (Redfern 2001a, pp. 18-20). 
Serious Incident Procedure and Record Keeping

After thoroughly looking into van Velzen abuses and the conditions which exacerbated them, Redfern established that the hospital had inadequately disseminated the news of improper retention to parents.

Alder Hey failed to provide honest face-to-face communication of the news of organ retention. It also failed to provide bereavement counselling and support for affected families (Redfern 2001a, p. 12).

The management of the retention news was far from adequate. News was drip fed. Information was often inaccurate. News of retention was commonly delivered insensitively (Redfern 2001a, p. 12). All of which greatly aggravated the original harm caused by improper retention. Many families affected had parts of their dead children returned to them on a piecemeal basis for reinterment over unacceptable periods of time, which further contributed to their suffering post-retention news.

Redfern recommended that Trusts introduce serious incident procedures (Redfern 2001a, p. 13). This involved appropriate forms of communication with those affected, who were to be communicated with in an open, honest and sensitive way. In order to handle the special sensitivity of such news it was recommended that bereavement experts be involved as a matter of course. Redfern also recommended overhauling the pathology record system, so that receipt use, and ultimate disposal of organ and tissue sample could be tracked at all times (Redfern 2001a, pp. 13-14).

\section{The Issue of Consent}

The Human Tissue Act 1961 (HTA) required clinicians to establish whether, after reasonable enquiry, they had any reason to believe that surviving relatives 'objected' to their kin being used for therapeutic purposes, medical education or research.

There is overwhelming evidence to show that the requisite demands of the HTA had not been met. In other words, clinicians had not made 'reasonable enquiries' to ascertain whether parents 'objected' to postmortem procedures, sometimes even ignoring their wishes and putting pressure on them to change their minds. Whilst Michael Redfern recognised the role that paternalism played in this, the Inquiry Report keenly points out that paternalism did not explain it away. Redfern points to the fact that clinicians 'lacked any proper consideration of the Act in the first place' (Redfern 2001a, p. 3). 
Redfern's aim was to make the consent more procedurally rigorous and a less conceptually ambivalent process. There was also a need to train and educate. Doctors needed educating and training in the taking of consent, and the public needed to understand why organs needed to be retained for medical research and educational purposes.

At the heart of Redfern's recommendations was a conceptual shift in the idea of consent (Redfern 2001a, pp. 23-24). Having a more robust law around consent was a way of changing the focus from clinical- to patient-centred interests.

The HTA was still a form of presumed consent because 'reasonable enquiry' to confirm 'no objection' carries with it a significant element of clinical presumption that post-mortems are acceptable. Redfern favoured a shift towards 'fully informed consent'. This moved the responsibility of decision-making away from the doctor and on to the parent or next of kin. This significantly improved consent in two ways.

Firstly, informed consent challenges the paternalistic attitude that 'doctor knows best'. This presumption was especially dangerous when it was assumed that the next of kin would be too distressed to discuss consent regarding a post-mortem.

Redfern identified paternalism as a deeply contributing cultural factor to the retention tragedy. Redfern took the view that not involving the parents in taking responsibility for post-mortem retention would only serve to increase future distress. Involving them, as the parental evidence suggests, might relieve the anger, resentment and guilt at having the decision taken away from them-the one caveat being that involving the parents in decision-making had to be done sensitively, allowing time and space for them to reach a stable decision that they could live with.

Secondly, informed consent also militates against clinicians from acting in their own self-interest. The reality at Alder Hey was that clinicians were often motivated by their own clinical or research interests. They were regularly blind to a deep parental need to have the corpse treated with respect, so that the integrity of the dead might be preserved wherever possible in line with the demands of normal grieving, religious belief and funerary custom.

\section{Beyond the Formal Conclusions of Redfern}

It is mistaken to think of the posthumous harm of retention too narrowly, as if it might somehow be reduced to a series of formal conclusions in a public inquiry. There are four mistakes that can be made. 
The first mistake is to think that improper removal, retention and storage are the only issues that matter concerning posthumous harm. Alder Hey represents a breakdown of trust in healthcare and can be reframed in such terms (Harrison et al. 2003; Pilgrim et al. 2011).

The second mistake is to think of retention at Alder Hey as an isolated occurrence. Liam Donaldson, the Chief Medical Officer, reported in February 2001 that improper retention and disposal of organs was widespread in the UK. Alder Hey got most of the bad press, and was probably only unique in the scale of retention and in the furore it caused. Importantly, Donaldson discovered that other NHS institutions around the UK were also guilty of flouting the HTA and improperly removing and retaining organs:

...elsewhere in the NHS it is clear that organ retention without relatives' full knowledge and agreement was widespread. The recent national summit on organ retention organised by the Chief Medical Officer, Professor Liam Donaldson, confirmed that this was also the experience of parents in many other parts of the country. Professor Donaldson's census shows that 105,000 organs are retained across the country. Poor standards of cataloguing and record-keeping mean that these figures may not be wholly accurate. Twenty-five thousand hospitals account for $88 \%$ of the organs. At least 16,500 of these organs and tissues have been retained in apparent contravention of the law because they came about as a result of coroners' post-mortems where the organs should not have been kept beyond the time needed to establish cause. (HL Deb. 2001, 621 c. 574)

The third mistake is to become overly focussed on the formal conclusions - especially the summary and recommendations of the Inquiry.

The summary and the full report generally concerns what went wrong at Alder Hey from an institutional point of view. An over-focus on institutional failure can lead to an inability to understand the impact of posthumous harm on its victims. For this we need to understand the more implicit and informal parental evidence to Redfern available from the full Inquiry Report.

The fourth mistake is to think of Alder Hey as historically unique. It is not. Lessons can be learned from the past, as well as from a public inquiry.

The idea of posthumous harm, it will be argued, repeats with a difference over time. Before looking into this in some depth towards the end 
of this chapter, and making historical comparisons with unconsented dissection in the nineteenth century, we need to understand the impact of posthumous harm through parental evidence to Redfern.

\section{Understanding the Parental Oral Evidence to Redfern}

The parental evidence falls into two broad analytical categories:

- A surface level of analysis in which what parents say to the Inquiry is fairly self-evident in respect to why it is harmful. This is illustrated by issues around consent and the spectrum of deceit;

- A deeper level of analysis where what parents say to the Inquiry is not so self-evident, but nevertheless gives important clues as to why posthumous harm matters to them. This is illustrated by issues around identity beyond biological death and how harm to memory and biography through dismemberment is possible in a narrative sense.

\section{Consent and the Spectrum of Deceit}

Parents were deceived by improper removal and retention of organs, either through the initial consent procedure or, by the hospital failing to inform and support parents properly afterwards. There is a whole spectrum of deceit evident through the parental evidence presented to Redfern.

At one end of the spectrum parents were lied to. For example:

Kathryn - 15 years Kathryn developed Hodgkin's disease and died at Alder Hey Hospital in 1993 ... On 8 December 1999, her parents were informed by Alder Hey that Kathryn's heart, chest and abdomen had been retained. On the 20 December 1999 they had received a letter from Ms Hilary Rowland, Chief Executive at Alder Hey, indicating the heart, lung, liver, liver, spleen and kidneys had been retained. In the post-mortem report Prof van Velzen said that only a small mid sternal incision approach was made with splitting of the caudal sternum. Only the upper organs and lower aspects of the chest organs were brought into view and inspected... Only organ biopsies were taken. This was a fiction confirmed by the list of organs described by Ms Rowland in her letter of 20 December 1999. (Redfern 2001b, pp. 396-397) 
Being deliberately lied to by clinicians like van Velzen was compounded by Alder Hey's inept handling of events. Parents had information withheld from them and were sometimes given contradictory information about retention. For example:

Anthony - 3 years 10 months Anthony was born with congenital heart disease. He died in 1996 within $24 \mathrm{~h}$ of major heart surgery... In late September 1999 they [the parents] contacted Alder Hey and although they were being treated professionally they always felt that certain information was being withheld. The hospital was evasive in certain areas... At first they were told that the heart had not been taken. As an afterthought they asked what tissue samples had been taken and to their surprise were told brain, stomach, one kidney and one lung. They were then contacted by the treating clinician who told them the heart had been taken as well. (Redfern 2001b, p.422)

Some parents interpreted the improper retention of their children's organs without consent as theft. For example:

Tony - 11 days Tony died in 1994. His precise cause of death is still under investigation. They [the parents] were told that there would be Coroner's post-mortem examination... When they rang Alder Hey in late 1999 to enquire if any organs had been retained they were told the following day that there had been retention. They asked what had been taken and the reply was 'everything basically'... His mother told the hospital that they had stolen the organs and she wanted a 100 percent guarantee that Tony's were not being retained, to which the hospital said 'alright you have got a 100 per cent guarantee' after previously refusing to give such a guarantee... (Redfern 2001b, p. 412 [author's italics])

Clinicians often did not explain the consent procedure and/or parents were too distressed to be able to give consent due consideration. Clinicians also readily conflated the meaning of taking tissue with organs, misleading parents into exactly how their children had been handled post-mortem and what had and what had not been taken. For example:

Ross - 5 months was born prematurely at 27 weeks and died in 1990 at Liverpool Maternity Hospital... His parents consented to a post-mortem examination to determine the cause of death if it would help other children who had the same disease. No steps were taken to explain the consent 
form to them. Because of their distress they describe signing it 'blind'. They realised that small samples would be taken from organs in the postmortem procedure but understood that to mean a small piece of tissue for microscopic examination. They were never told whole organs would be removed and retained... They thought they buried their son intact whereas in fact they buried a husk. (Redfern 2001b, p. 399)

A mother felt that Alder Hey had deliberately used 'tissue' as a euphemism in order to remove whole organs. For example:

Ryan - 19 days Ryan was born with congenital heart disease. He died following open-heart surgery in 1995 at Alder Hey... They feel they used the word 'tissue' when it suited them, and if they were looking to have an organ from a child and put it another child that would have been organ donation but because the organs have been retained for medical research purposes they are then classed as tissue samples. The mother is unhappy at this false distinction. (Redfern 2001b, p. 432)

\section{Personal Identity and Its Continuation Beyond Death}

One commonplace misconception is that an individual's identity ends at biological death and is no longer a relevant 'fact' post-mortem. For example:

Sam - 18 months Sam was born with congenital heart disease. He died in surgery in 1990 at Alder Hey. A coroner's post-mortem examination was carried out. The post-mortem examination was not explained to his parents... They received news of organ retention in January 2000. Eventually they were told there had been full retention... The impression given by Alder Hey was that an individual's identity ends at a post-mortem examination if not death... (Redfern 2001 b, p. 425 [author's italics])

Death from a clinician's perspective tends to revolve around the notion of biological death only. Their raison d'être is to save life and do no harm. The desire to save life at Alder Hey went hand in hand with a caring attitude to parents of sick children.

Several Alder Hey parents observed the contrast between the high quality of care their children received in life compared to in death (Redfern 2001b). The lack of care towards the dead by clinicians at Alder Hey was compounded by their training. In the words of a nurse communicating the news of organ retention to a parent: 'try not to look 
at this emotionally it is just tissue' (Redfern 2001b, p. 414). While factually true at the level of biological death, it shows a lack of empathy and understanding of grief when care of the recently deceased naturally continues.

\section{Posthumous Harm as Narrative or Symbolic Harm to the Dead}

At a more conceptual level of understanding, the corpse is both a physical unity and a locus of symbolic meanings. For parents the corpse of their recently deceased child is imbued with intimate memories and associations. For a pathologist, on the other hand, the corpse as a cadaver accrues objective and scientific understanding of the cause of death. Ideally, of course, the clinician needs to understand both perspectives: her own scientifically motivated one, as well as that of the next of kin, who are still emotionally attached to the deceased. This flexibility of perspective was lacking at Alder Hey.

One of the most striking pieces of evidence to Redfern describes how a mother's memory of her deceased child has been 'ruined' by inappropriate removal and retention of his organs. For example:

Kenneth - 5.5 weeks Kenneth died in 1987... In December 1999 his mother contacted Alder Hey and two weeks later was told that the heart only had been retained... The family has been bitter at the discovery of heart retention... She says that the memory of her child has been ruined by living under the illusion that he was buried intact when in fact he was missing his heart. She cannot even look at pictures of him now because she just sees him in a different way. (Redfern 2001b, pp. 410-411 [author's italics])

From the perspective of Kenneth's mother, the removal of Kenneth's body parts without her permission was perceived as posthumous harm. That is, body parts like the heart, eyes, hands represent relationships with significant others symbolically inscribed. So, if body parts are missing, such as the heart, then harm has been done, because body parts represent the memory of a deeply personal relationship (Dickenson and Widdershoven 2001, Tomasini 2009). The improper retention of Kenneth's heart affected his mother's capacity to remember him as he was. This is probably exacerbated in the case of babies and infants, where the memory of that child is yet to be properly established. So any inappropriate dismemberment is going to affect the particular association and fragile preciousness of any early biographical memory acquired. It is 
also harm to hope and future life; that is, the hope that parent holds for that child's future and the memory of an imagined and anticipated life together with that child as they grow up in a family.

The idea of posthumous harm for those parents affected by Alder Hey 'complicated grief'. Complicated grief constitutes both symbolic and intinsic harm. The symbolic harm through desecration of the body is a vector for a more complicated and psychologically distressing grief.

Complicated grief involves parental guilt at not protecting their child from harm post-mortem. That is to say, the clinical deception that allowed clinicians to remove organs without proper consent made parents feel guilty that they had not 'protected' their loved ones in death. For example:

Sam 18 months: "They feel that they protected their child in life, but in death when he needed their protection more than ever, they feel guilty they let him down in allowing or permitting organ retention." (Redfern $2001 \mathrm{~b}$, p. 425 [author's italics])

From a biological view of death this is quite unintelligible as no harm can befall the dead, so why protect them?

Perhaps this is why some clinicians at Alder Hey seemingly lost interest in the dead, not showing the same amount of care to recently deceased children, when every effort was extended to save their life. Unsurprisingly, many clinicians are so conditioned into saving lives that some may overlook the needs of grieving parents and their overwhelming desire to 'protect' their dead.

From the perspective of social death 'protecting' the dead is perfectly intelligible as a recently deceased person retains a narrative identity; that is, body parts are symbolically inscribed with interpersonal memories, so if those parts are damaged or go missing, parents feel guilty at not 'protecting' the memory of their child.

This idea of the 'continuing bond' between living and the dead is well established in the literature (Klass et al. 1996). The 'continuing bond' needs to be protected in both a literal and figurative sense. Failing to protect the physical integrity of the dead potentially affects memory and their narrative identity after life. In short, inappropriate dismemberment amounts to symbolic harm.

The symbolic harm of dismemberment was further complicated for parents who had strong religious beliefs. The misplaced paternalism and 
insensitive attitude at Alder Hey often deeply affected parents, denying them their need to take control of the funeral and bury their children whole according to, for example, their Catholic religious beliefs and funerary customs. For example:

Christopher - Stillborn Christopher (stillborn) Christopher was born prematurely stillborn in 1987. He was taken away at birth... The hospital insisted that the baby be buried in hospital grounds. They [the parents] were told that it would be a dignified ceremony. They asked if they could see their son buried. They were told that it would not be possible and that seeing the burial grounds would only upset them. They were told to have another child. The parents had no control over what happened to Christopher. They wanted to bury him themselves. They are a Catholic family and burial is important to them. To bury their child intact is part of their religious belief... (Redfern 2001b, p. 430 [author's italics]).

Not only were Christopher's parents dealt with extremely insensitively, to the point where clinical patriarchy borders on being callous, but the behaviour showed no understanding of the funeral ritual and the part this plays in the religious beliefs that the parents had.

From the formal perspective of Catholic doctrine dismemberment could be interpreted as future-orientated symbolic harm. That is, Catholic doctrine encourages belief in the integrity of human remains for burial in consecrated ground for the sake of resurrection at the Last Judgment. The implication is that to deny resurrection of the body is to deny the Resurrection of Christ (Burke 2016).

This, of course, does not explain why exactly Christopher's Catholic parents wanted to bury their child intact. While the evidence needs to be taken at face value, such Catholic doctrine at least provides a clue as to why not interring a person whole might provoke anxiety and fear amongst devout Catholics.

\section{Posthumous Redemption Narratives: Failures and Successes}

Because of the harm perpetrated by the organ retention scandal at Alder Hey, it is easy to overlook the redemptive narratives that may have motivated clinicians in their wrongful attempts to remove and retain organs post-mortem.

Anonymous body parts have a redemptive narrative in the history of medicine, either directly, through saving another's life through cadaveric 
organ donation, or indirectly by helping science understand the cause and course of disease. Retention of organs and tissue from cadavers would also have provided a resource in the teaching of medical students.

Looking more specifically at the Alder Hey case, the taking of organs post-mortem could have had a redemptive affect if parents had been asked properly and the organs had been put to some use in saving other lives in some way.

Richardson has claimed that parents might well have given their permission if they had been asked properly (Richardson 2001, p. 416). From the oral evidence to Redfern, some parents were clearly overcome by the shock of loss, and without any bereavement support or any time to process the information many made decisions that they came to regret and feel guilty about later (Redfern 2001b, pp. 388-434). Others, who did consent to limited post-mortems, expressed preferences in their desire to help others in some practical way. The narrative of a child's life continues on after life, in 'the gift of life'-where a donor's organs may save the life of sick child awaiting a transplant. The importance of 'the gift of life' is well established in the literature on attitudes to donation. Indeed, the 'sacrifice' of a parent giving up their dead for donation or research purposes is outweighed by the prospect that it may be understood as a 'gift of life'-helping another sick child in some way (Sque et al. 2006, pp. 117-131). Put another way, no parent affected by the Alder Hey retention scandal gave permission for their children's organs and tissue to stored and left unused in the basement at Myrtle Street.

If the redemptive act of saving another life through organ retention had some potential-both as an intrinsic fact in the preserving biological life where it was failing, and as a symbolic one in continuing the narrative of the life of an ailing donor-much of this was a wasted opportunity at Alder Hey, where organs and tissue piled up, unused, in storage.

Interestingly van Velzen was interviewed in 2001 (Dickson 2001) about his role in the whole debacle. He maintained that his motivation in removing organs wholesale 'was demanded by standard international protocols' and that the growing collection was to be used for future research purposes yet to be determined.

He claimed that the 'organs piled up' when the money ran out and that he no longer had the support he needed to keep on top of his 
day-to-day clinical case load. At no point did he say he was wrong or did he say he was sorry (Dickson 2001).

It is difficult to give much credibility to van Velzen's justifications. What is more probable is that van Velzen was in what Sartre would call 'bad faith' (Sartre 2005) about his role in the retention scandal. While van Velzen was not the only person that deserved to shoulder blame, he seems to have been afflicted by a 'moral blindness' years after the facts had come to light.

The only practically redemptive narratives which stand out at Alder Hey are lessons learned from the tragedy itself. Indeed, the Bishop of Liverpool, who paid tribute to the victims of Alder Hey in a special service for its victims proved prophetic. In his address he thanked 'God for the parents' courage and restraint.' He 'promised that their children's deaths and their own sufferings had not been in vain: their courage to confront and expose illicit behaviours meant that things would be different, and better, in the future' (cited in Richardson 2004, p. 45 ).

This was prophetic. Redfern paved the way for many radical and helpful changes to safeguarding against posthumous harm of this kind. It also provided a cornerstone for a radically revised HTA (2004) that introduced the notion of fully informed consent procedures. This not only affected how post-mortems were conducted, it signalled how other procedures were conducted in the NHS, paving the way for a wider cultural change away from medical paternalism and towards a more patient-centred approach where responsibility is more equally distributed.

\section{A Historical Long-View of Posthumous Harm and Redemption: Alder Hey}

The character of posthumous harm repeats with a difference over time. It is not a notion that is historically unique to Alder Hey. To understand how the character of posthumous harm over time repeats with a difference, it is helpful to offer a comparative account: body-snatching in the Georgian period versus organ-snatching in the late twentieth century at Alder Hey. 


\section{A Historical Long View of Posthumous Harm: Comparing Body- Snatching to Organ-Snatching}

\section{Improper Procurement and Retention}

Taking organs of dead children without parental permission at Alder Hey is a practice The Economist (2001) dubbed the 'return of the bodysnatchers'. There is a historical parallel to be drawn between the practice of body-snatching in the Georgian period and 'organ snatching' at Alder Hey some two hundred or so years later.

As regards the law both body and organ 'snatching' were illicit rather than straightforwardly illegal practices. The removal of corpses from graves by the 'resurrection men' was not illegal before the Anatomy Act, although stealing from the corpse and or 'knowingly' dissecting the corpse was. It would be more precise to say that body-snatching was an 'extra-legal' activity (Richardson 2006, p. 155).

The removal of organs at Alder Hey for the most part was also not (straightforwardly at least) illegal. The pathology team at Alder Hey seemingly went through the legal motions of securing consent for postmortems from parents of dead children. After the scandal broke, the retention issue was deemed unlawful and parents secured a successful legal challenge against the removal of their children's organs.

Even though 'organ-snatching' did not involve anything as dramatic as stealing a corpse from a grave in the dead of night, it did, under the cloak of seeming medical respectability, amount to something similar to body-snatching. That is, from the perspective of family and friends the removal of organs without parental permission was sometimes experienced as an act of theft. In the case of body-snatching, bodies of the recently deceased were stolen out of graves to the chagrin of those watching over them.

\section{The Commodity Value of the Cadaver}

The motivation behind organ-snatching and body-snatching is similar: that is, human material post-mortem has a strong commodity value, even though what is valauble about the human corpse changes over time.

The transformation of the cadaver to an object of trade-commodification-took off in the body-snatching era, when the gallows provided nowhere near enough bodies required for teaching and research 
purposes. Demand outstripped supply and opened up a lucrative market for human remains to anatomy schools (Richardson 2001a, pp. 52-72).

The corpse represented monetary value to the body-snatcher. From the perspective of the anatomist, the corpse is a cadaver, meaning a dead body intended for dissection. The change of signification of corpse to cadaver for dissection and anatomization is interesting and important to understand.

The corpse that had straightforward capital value to a body-snatcher becomes, in the hands of the anatomists, a cadaver which has both 'cultural capital'-the body as a resource for medical knowledge, education and skills - and 'symbolic capital' (Bourdieu 1986) - the body as resource that confers professional legitimization, recognition, honour and prestige. In sum, the transition of corpse to cadaver is a form of translation of capital in the process of commodification.

The procurment of specific kinds of post-mortem human material is driven by the state of medical science and its demands, which changes over time.

The establishment of the NHS in 1948 coincided with altruistic donation with the result that demand and supply levelled out for the first time (Richardson 2006). However, the high commodity value of human material repeats with a difference in the second half of twentieth century as organ donation takes off. By the end of the twentieth century, once organ donation and transplantation surgery become fairly routine, the demand for human organs from recipients needing transplantation surgery outstrips the supply of those willing to donate.

This pattern, to some extent at least, is replicated in pathology where the demand to take organs from the dead for research purposes was voracious, especially at institutions like Alder Hey. During van Velzen's tenure the culture of 'taking every organ in every case' (Redfern 2001a, 2001 b) was partly driven by the promise of cultural and symbolic capital gained through research. More surprisingly still, at Alder Hey there were echoes of the earlier culture of body-snatching for straight profit. Alder Hey sold cadavers for five pounds apiece to a pharmaceutical company wanting their pituitary glands in order synthesise human growth hormone (Hurren 2002).

Finally the improper retention of organs was not isolated to the one institution, Alder Hey. Improper retention was a UK wide occurrence (Donaldson 2000). This also resonates with the Georgian period when body-snatching was a widespread phenomenon; and while potentially 
it threatened all classes, it actually most affected the poor who could ill afford to secure the grave from the body-snatchers.

\section{The Moral Ambivalence of the Collectors of Human Material Over Time}

Another historical resonance between body and organ-snatching lies in the morally ambivalent character of medical men such as John Hunter and Dick van Velzen, who were keen to profit from the improper removal of human remains.

John Hunter gained cultural and symbolic capital from the cadaver. Respected in his time, he became a Fellow of the Royal Society in 1767 and today is lauded as being the 'father of modern surgery' and is recognised for his careful observation and scientific method in medicine. As an army surgeon, Hunter contributed to an understanding of gunshot wounds and their early treatment. Post-army, Hunter became an acclaimed pioneer of early transplantation surgery, and he worked on the transplantation of human teeth (Moore 2010).

Hunter is a morally ambivalent character. On the one hand he is lauded for his skills and pioneering work in medicine. On the other hand he can be rightly criticised for his morally questionable methods. Hunter employed agents to obtain stolen human bodies and body parts. He financially induced living donors (often minors) to secure living teeth, which he would implant into wealthy paying adults. Hunter continued his work despite many set-backs where it was clear that he was harming his patients. Perhaps most worryingly, he was blind to such failures and seemingly impervious to ethical criticism (Richardson 2006, p. 159; Moore 2010).

If we look at Dick van Velzen, who became the villain at the heart of retention scandal at Alder Hey, there is scope for comparison.

Both Hunter and van Velzen were prominent social actors in historically conjoined, yet distinctive disciplines. This—as Richardson first pointed out-is relevant by virtue of the fact that pathology evolved from 'morbid anatomy' (Richardson 2006).

Hunter was a practitioner of morbid anatomy and a surgeon, whilst Van Velzen was a professor of paediatric pathology. Like Hunter, van Velzen was actively involved in the improper removal of human material. Hunter paid agents to illicitly procure bodies. Van Velzen directly participated in 'organ theft' by flagrantly abusing consent procedures and lying to parents about the extent of his post-mortems. Again, like Hunter, his motivation seems to have been research led. 
Unlike Hunter, van Velzen's research ambitions came to nothing as human materials remained in storage unused. Van Velzen will be remembered as a notorious nonentity. By contrast Hunter is acclaimed as a pioneer because of his contribution to anatomy and 'the birth of modern surgery' (Moore 2010).

Perhaps the most interesting similarity between the two men is their moral blindness. In the transplantation of teeth to live donors, Richardson refers to 'Hunter blindness'; that is, 'the ability to focus so narrowly on recipient benefit as to excise the humanity of the donor from contemplation' (Richardson 2006, p. 159). Van Velzen also seems to have developed a similar form of moral blindness, dogmatically defending his virtue as a researcher and consistently maintaining that he had done 'nothing wrong' in removing and retaining organs from the dead children of distraught parents post-mortem, despite overwhelming evidence to the contrary (Dickson 2001).

\section{Complicated Grief}

Richardson states that 'like grave-robbery for dissection, organ procurement necessarily impinges upon the fresh grief of bereaved relatives and friends' (Richardson 2001 a, p. 413). However, in her afterword to Death Dissection and the Destitute there is no space for further explanation.

Some clues are provided in the parental oral evidence to Redfern (2001b) as to why such posthumous harm was so heartfelt and psychologically damaging. Comparisons may be drawn here to body-snatching in earlier times. In this evidence parents challenge the fact that personal identity ends at death. The mother of Sam, who died at 18 months, puzzles whether Alder Hey understood an 'individual's identity' to end 'at a post-mortem examination, if not death' (Redfern 2001b, p. 425).

For the parents of the child victims of improper retention, the capacity to remember their dead was deeply affected by dismemberment. It is highly likely that body-snatching, some 200 years earlier, would also have complicated grief in a similar way, although there is next to no direct historical evidence surviving of the internal lives of ordinary people to support such a claim.

\section{Public Furore and Parliamentary Intervention}

The more evidentially obvious comparison to be made between bodysnatching and organ-snatching is in the high-emotion and public furore that both caused. 
Bodily theft and respect for the dead generated high emotion and visible public commotion in the Georgian period. For example, catching a body-snatching gang at Lambeth in the district of London in 1795 was reported as:

“"people of all descriptions, whose relatives had been buried ... demanded to dig for them ... in great numbers forced their way in, and in spight of every effort the parish Officers could use, began like Mad people to tear up the ground ...' 'Great distress and agitation of mind was manifest in every one, and some, in a kind of phrensy, ran away with their coffins of their deceased relations." (cited in Richardson 2004, p. 935)

Furthermore, in early January 1832 high emotion led to protest and public violence. A full scale riot erupted at an Anatomy School in Aberdeen, which led to violence, looting, and the school's eventual destruction by being burnt down to the ground (Richardson 2001a, pp. 90-91).

The events at Alder Hey also spawned high emotion and a public furore-though it did not lead to public disorder, violence and the burning down of a medical school. In the case of the organ-snatching, anger was organised through the interest-cum-pressure group PITY2 that spoke truth to power. Parents talked of having their children 'butchered' and 'desecrated' post-mortem without their consent. Many also talked of the hospital having 'betrayed their trust' (Redfern 2001b).

Another interesting comparison between the two cases is how public outrage finally leads to parliamentary intervention. In both cases parliament acted once medical personnel and medical institutions became implicated and incriminated.

An important factor that led from popular protest against the bodysnatchers to the select committee that officially looked into the issue was the prosecution and conviction of an anatomist in 1828 for unlawfully conspiring to obtain and receive a body. The proven collusion between an anatomist and resurrectionists 'effectively incriminated anatomical enquiry, and at last caused Parliamentary action to be taken' (Richardson 200lb).

Likewise, once a medical institution was implicated, parliament was forced into a formal investigation of organ retention in the Alder Hey case. Once Ms. Rowlands could no longer reassure parents that the organ retention issue was isolated, insignificant, and media attention 
forced the issue up the political agenda, both the hospital and van Velzen were incriminated in the ensuing Public Inquiry.

\section{Cultural and Religious Taboo}

The final comparison worth drawing is both body-snatching and organsnatching violated certain cultural and religious taboos.

In the eighteenth century body-snatching violated both cultural and religious taboos by running roughshod over complex funerary customs that existed in caring for the dead. The notion of a 'decent' funeral had strong cultural currency and was deeply entangled in how the dead needed to be treated in order to ensure safe passage in a life hereafter.

With the decline of religion and folkloric belief in the nineteenth and twentieth centuries, comparisons may seem difficult to make. Nevertheless, even in the highly secular times where science supposedly outs belief and superstition about a life hereafter, Alder Hey demonstrates that dismembering the dead was still culturally and religiously taboo.

Many of the Alder Hey parents affected were Catholic and were intent on having a 'decent' funeral, even if it meant multiple funerals in order to bury their children whole. For example, from the parental evidence from the family of Philip ( 5 years 3 months) to Alder Hey:

The first funeral was a Catholic burial. The Church was packed with friends, family and work colleagues. Their son should have been buried intact. His body was desecrated. The second funeral was very low key. Seven people attended. Their son could not face the second funeral. They feel that the first funeral was indecent. They were not sure what they were burying at the second funeral. (Redfern 2001b, pp. 425-426 [author's italics])

The unauthorised removal of Philip's organs was perceived as desecration of his body. This is significant because the word 'desecration' has a double meaning: the harming of 'someone that is dear and loved' and the harming of something that is 'sacred and revered'. It is quite possible therefore, that the desecration of the dead at Alder Hey, in the eyes of Catholic families, deeply contravened their religious belief, as well as complicated grief by affecting their capacity to truly remember them. 


\section{SUMMARY}

This empirical chapter has historically illustrated posthumous harm and redemption. Posthumous harm and redemption have been understood in three ways.

In contemporary form, posthumous harm has been illustrated through the improper removal, retention and disposal of organs at Alder Hey in the 1990s. This has been interpreted in the following ways:

First, from the formal perspective of the Redfern Inquiry, which provides a broad outline of why and how improper retention can be understood as posthumous harm at the level of procedures and institutions.

Second, from the informal perspective of the parental oral evidence to the Redfern Inquiry, which provides a deep insight into why the improper retention of dead children's organs and tissues mattered so much to parents in the first place.

Third, from the perspective of a historical long view, which compares and contrasts body-snatching with the practise of organ-snatching at Alder Hey.

\section{REFERENCES}

Anonymous. (2001). Return of the body snatchers. The Economist. Retrieved May 2, 2016, from http://www.economist.com/node/492949.

Batty, D. (2001, January 30). Alder Hey report on use of children's organs. The Guardian. Retrieved February 4, 2016, from http://www.theguardian.com/ society $/ 2001 /$ jan $/ 30 /$ health.alderheyl.

Bourdieu, P. (1986). The forms of capital. Retrieved May 2, 2016, from https:// www.marxists.org/reference/subject/philosophy/works/fr/bourdieu-formscapital.htm.

Burke, R. (2016). On the Christian burial of the dead. Retrieved May 2, 2016, from https://www.catholicculture.org/culture/library/view.cfm?recnum $=3448$.

Dickenson, D., \& Widdershoven, G. (2001). Ethical Issues in Limb Transplants. Bioethics, 15(2), 110-124.

Dickson, N. (2001). Van Velzen interview in full BBC News. Retrieved May 2, 2016, from http://news.bbc.co.uk/2/hi/health/1154181.stm.

Donaldson, L. (2000). Report of a census of organs and tissues retained by pathology services in England. London: Stationary Office.

Hall, D. (2001). Reflecting on Redfern: What we can learn from the Alder Hey story? Archives of Disease in Childhood, 84, 455-456. 
Harrison, J., Innes, R., \& Zwanenberg, T. (2003). Rebuilding trust in bealthcare. Abingdon: Radcliffe Medical Press.

House of Lords Hansard Debates. (2001). The Alder Hey Inquiry Report 30 th Jan 2001. 621 c. 574. UK Parliament. [Online]. Retrieved February 4, 2016, from http://www.publications.parliament.uk/pa/ld200001/ldhansrd/vo010130/ text/10130-06.htm.

Hurren, E. (2002). Patients' rights: From Alder Hey to the Nuremberg Code. History \& Social Policy. Retrieved May 2, 2016, from http://www.historyandpolicy.org/policy-papers/papers/patients-rights-from-alder-hey-to-thenuremberg-code.

Klass, D., Silverman, R., \& Nickman, S. (1996) Continuing bonds: New understanding in grief. New York London: Taylor \& Francis.

Moore, W. (2010). The knife man: Blood, body-snatching and the birth of modern surgery. London: Bantam Books.

Pilgrim, D., Tomasini, F., \& Vassilev, I. (2011). Examining trust in healthcareA multi-disciplinary perspective. Basingstoke: Palgrave.

Redfern, M. (2001a). The Royal Liverpool children's inquiry report-Summary \& recommendations. London: Stationary Office.

Redfern, M. (2001b). The Royal Liverpool children's inquiry report. London: Stationary office.

Richardson, R. (2001a). Death,dissection and the destitute. London: Phoenix Press.

Richardson, R. (2001b). Body-snatchers. In C. Blakemore \& S. Jennett (Eds.), The Oxford companion to the body. Oxford: Oxford University Press. Retrieved May 2, 2006, from http://www.encyclopedia.com/topic/body_snatching. aspx.

Richardson, R. (2004). Bodily theft past and present: A tale of two sermons. Lancet: Medicine, Crime and Punishment, 364, 44-45.

Richardson, R. (2006). Human dissection and organ donation: A historical and social background. Mortality, 11(2), 151-165.

Sartre, J.-P. (2005). Being and nothingness: An essay in phenomenological ontology. (H. Barnes, Trans.). London: Routledge.

Sque, M., Payne, S., \& Clark, J. Gift of life or sacrifice? (2006). Key discourses to understanding organ donor families' decision-making. Mortality, 11(2), $150-165$.

Tomasini, F. (2009). Is post-mortem harm possible? Understanding death, harm and grief. Bioethics, 23(8), 441-449. 
Open Access This chapter is licensed under the terms of the Creative Commons Attribution 4.0 International License (http://creativecommons. org/licenses/by/4.0/), which permits use, sharing, adaptation, distribution and reproduction in any medium or format, as long as you give appropriate credit to the original author(s) and the source, provide a link to the Creative Commons license and indicate if changes were made.

The images or other third party material in this chapter are included in the chapter's Creative Commons license, unless indicated otherwise in a credit line to the material. If material is not included in the chapter's Creative Commons license and your intended use is not permitted by statutory regulation or exceeds the permitted use, you will need to obtain permission directly from the copyright holder.

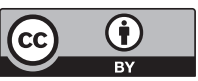

